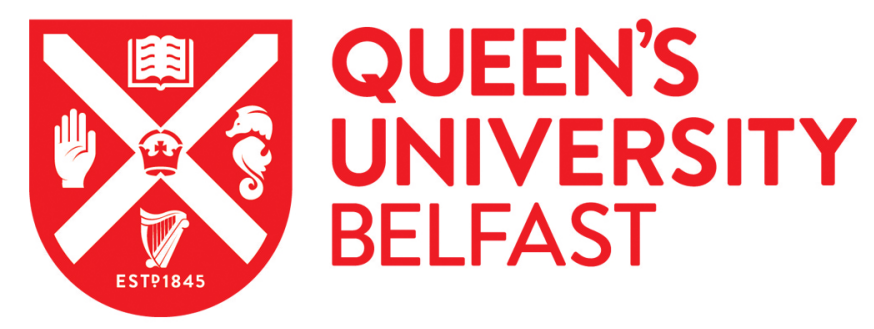

\title{
Chinese Authorial Identity: a Model for Scoring the Student Authorship Questionnaire
}

Ballantine, J., Guo, X., Larres, P., \& Yu, M. (2018). Chinese Authorial Identity: a Model for Scoring the Student Authorship Questionnaire. Studies in Higher Education, 43(12), 2385-2397. [2397].

https://doi.org/10.1080/03075079.2017.1333493

Published in:

Studies in Higher Education

Document Version:

Peer reviewed version

Queen's University Belfast - Research Portal:

Link to publication record in Queen's University Belfast Research Portal

Publisher rights

(C) 2017 Society for Research into Higher Education.

This work is made available online in accordance with the publisher's policies. Please refer to any applicable terms of use of the publisher.

\section{General rights}

Copyright for the publications made accessible via the Queen's University Belfast Research Portal is retained by the author(s) and / or other copyright owners and it is a condition of accessing these publications that users recognise and abide by the legal requirements associated with these rights.

Take down policy

The Research Portal is Queen's institutional repository that provides access to Queen's research output. Every effort has been made to ensure that content in the Research Portal does not infringe any person's rights, or applicable UK laws. If you discover content in the Research Portal that you believe breaches copyright or violates any law, please contact openaccess@qub.ac.uk. 


\title{
Chinese Authorial Identity: a Model for Scoring the Student Authorship Questionnaire
}

\author{
Joan Ballantine*, Xin Guo**, Patricia Larres*** and Miao Yu**** \\ *Ulster University Business School, University of Ulster, Jordanstown campus, \\ Shore Road, Newtownabbey, Co. Antrim, BT37 0QB \\ **School of Business and Enterprise, University of the West of Scotland, \\ Hamilton, UK, ML3 0JB \\ ***Queen's University Management School, Queen's University, \\ 185 Stranmillis Road, Belfast, BT9 5EE \\ ****Beijing Union University, Beijing, China
}

* Address for correspondence: Joan A. Ballantine, Professor of Accounting, Department of Accounting, Room 03C23, University of Ulster, Jordanstown campus, Shore Road, Newtownabbey, Co. Antrim, BT37 0QB, Telephone: +44 (0)28 90366204 , Fax: +44 (0)28 90368502, e-mail joan.ballantine@ulster.ac.uk 


\begin{abstract}
This study explores authorial identity and plagiarism among Chinese students studying accounting and business in China by drawing on Pittam et al.'s (2009) Student Authorship Questionnaire (SAQ). Chinese students' attitudes to authorship and plagiarism are reported as being similar to those of UK students from the same disciplinary background. This finding challenges the traditional view that Chinese students, because of cultural influences, are less likely to take ownership of their writing and more accepting of plagiarism than western students. The study also investigates the psychometric properties of the SAQ in the context of Chinese students and offers a distinct Chinese model for scoring the instrument which takes account of Chinese students' approaches to writing and, in particular, reflects the paradox of the Chinese learner.
\end{abstract}

\title{
Keywords
}

Authorial identity, plagiarism, approach to writing, Chinese paradox, Student Authorship Questionnaire 


\section{Introduction}

The UK attracts more new international students to higher education each year than any other country, with by far the largest number coming from China (Peak 2015). Reference to recent statistics produced by the Higher Education Statistics Agency (HESA 2016) confirms that during the academic year 2014-15, 89,540 Chinese students enrolled in UK higher education courses, with business and administrative studies proving to be the most popular subject (UKCISA 2016). This figure represents a $2 \%$ increase on the previous year. However, this development is not without its challenges. In particular, western educators have voiced concerns about academic integrity among Chinese students, with a specific focus on plagiarism (Hu and Lei 2015). One well-publicised incident resulted in a Yale professor speaking out about Chinese students 'stealing words and ideas from an author without acknowledgment' (The Economist 2013). Recently, in the UK, Queen Mary University of London, reported that $75 \%$ of postgraduate students caught plagiarising were from abroad, and of those, a third came from China (Aftab 2016). These examples represent a general perception in academia that Chinese students are 'persistent perpetrators' of plagiaristic behaviour (Martin 2012, 262). However, while accepting that such allegations must be taken seriously, warnings against generalizations 'degenerating into stereotypes' have also been voiced (Sowden 2005, 228). Hu and Lei (2015) point out the inappropriateness of 'assuming deficiencies in moral frames of reference' and how 'it is imperative and instructive to conduct empirical investigations into what conceptions Chinese students have of plagiarism' (233). To this end, the current study contributes to the limited extant literature in this 'grossly underresearched' area (Ehrich et al. 2016, 231) by focussing on the authorial identity of Chinese accounting and business students based at three Beijing universities: the premise being that a confident assured authorial identity reduces plagiarism (Abasi, Akbari, and Graves 2006). Further, by selecting Chinese students who are studying in their first language, the likelihood 
that second language-related problems may lead to inadvertent plagiarism is eliminated and the focus remains concentrated on informing awareness of authorial identity and plagiarism. The Chinese students' authorial identity is scored using the Student Authorship Questionnaire (SAQ) (Pittam et al. 2009) and compared with the authorial identity of UK accounting students reported in a recent study by Ballantine, Guo, and Larres (2015). Given that both sets of students are studying in the same disciplinary area, the comparison provides interesting insights into the relative sense which Chinese students have of themselves as authors, including their attitudes to plagiarism, vis-à-vis UK students. The psychometric properties of the SAQ in the context of Chinese students are also investigated to produce a distinct model for scoring the SAQ which takes account of the paradox of the Chinese learner.

\section{Plagiarism and the Chinese learner}

It has been suggested that Chinese students encounter problems in Western classrooms when required to engage in original thinking (Chan 1999), a shortcoming often attributed to a focus on rote learning. The premise is that overexposure to memorizing facts stifles Chinese students' ability to marshal original thoughts. However, bearing in mind that literacy in China involves learning in the region of 3,000 characters, the need to develop memory skills is self-evident. Moreover, Confucian tradition promotes memorization through repetition as a pedagogy for reinforcing understanding (Cooper 2004). Accordingly, while the Chinese learner appears to adopt a surface approach to learning wherein he/she imbibes knowledge through rote learning to reproduce content in an exam, he/she is, in fact, applying memorization reinforcing techniques to achieve deep knowledge (Biggs 1994), a phenomenon known as the paradox of the Chinese Learner. According to the paradox, 
Chinese students excel as academic achievers, accomplishing deep learning by adopting a surface-based approach.

In addition to the epistemological emphasis placed on imitation and memorization as learning strategies, Chinese students are discouraged from engaging in 'verbal debate and argumentation' [as] 'meaningful tools for understanding truth and reality' (Peng and Nesbitt 1999, 747). The hierarchical structure of Confucian tradition, wherein lower order displays due deference and obedience to higher order, creates a society in which authority is revered and age respected. The egalitarian notion of challenging authoritarian views, whether from a teacher or a published source, is alien to Chinese students. In such a cultural setting, critical thinking among students is unlikely to flourish. Moreover, Chinese tradition perceives knowledge as a public good rather than individual intellectual property. Accordingly, the potential for Chinese students to take someone else's original ideas and pass them off as their own is heightened. Consequently, when introduced to the Anglo-Saxon academic practice of intertextuality, Chinese students tend to plagiarise (Lei and $\mathrm{Hu} 2015$ ). Moreover, definitions and examples of plagiarism are determined by Western norms. Therefore, while much has been written about Chinese students at western universities being more accepting of plagiaristic behaviour (Shi 2004; The Economist 2013), such reports have 'examined Chinese students' attitudes toward what is regarded as plagiarism in Anglo-American academia without considering their knowledge of it' (Hu and Lei 2012, 818). A lack of awareness of the conventions and mores of Anglo-Saxon academic writing may lead Chinese students to engage unwittingly in plagiarism, rendering it unintentional.

However, recently higher education in China has been undergoing change as part of a wider objective by the Chinese government to build national strength through science and education 
(Yang and Welch 2012). A key strategy in developing an internationally reputable higher education system has been the implementation of national initiatives such as ' 211 ' and ' 985 ' which aim to promote academic excellence by funding projects such as establishing research centres, hosting international conferences, attracting international scholars and facilitating Chinese scholars' visits abroad. Moreover, the Ministry of Education of the People's Republic of China has taken steps to tackle the issue of academic dishonesty directly, and address the damage it inflicts on the international reputation of Chinese universities (Sharma 2013), by issuing regulations on academic misconduct (see for example The Ministry of Education of the People's Republic of China 2009, 2012). These regulations explicitly identify plagiarism as an academic transgression which merits severe penalties. Accordingly, many Chinese universities have established punitive policies with respect to plagiarism and are employing text-matching programs to detect plagiarism in students' coursework (Hu and Lei 2015). Evidence of the impact of the recent regulations is beginning to emerge. For example, in a survey of 1,097 students studying at 16 Chinese universities, Ma, McCabe, and Liu (2013) reported that the students viewed strict enforcement of academic integrity policies as a deterrent from engaging in cheating behaviour including plagiarism. Also, a study by Guo, Man, and Hao (2013) which examined 604 undergraduate dissertations at a Chinese university reported that effective educational management procedures, including the use of plagiarism detection software and enforcement of strict penalties, led to a significant reduction in plagiarism among students.

It should be noted that a lack of awareness of what constitutes plagiarism is not confined to Confucian culture. Students, irrespective of cultural background, often have difficulty assimilating the diverse textual practices associated with academic writing (Pecorari and Petrić 2014). As novice writers, students are often apprehensive about incorporating others' 
opinions into their prose in case they unwittingly commit plagiarism (Ballantine, Guo, and Larres 2015). According to Hu and Lei (2012) this developmental perspective on plagiarism represents a trajectory of learning that all novices take to appropriate text legitimately and become competent academic writers. It compares with a cultural perspective wherein [Chinese students] 'experience complicated, nonlinear trajectories as they are socialized into [Western] academic discourse' (Duff 2010, 182). Nonetheless, both perspectives identify plagiarism as a developmental construct (Hu and Lei 2012). To this end, plagiarism resulting from authorial naivety and lack of experience in intertextual discourse represents unintentional plagiarism which should dissipate as the student develops an authorial identity (Abasi, Akbari, and Graves 2006). Accordingly, the research question which emerges from the forgoing discussion is whether Chinese students' authorial naivety, vis-à-vis UK students, is conflated because of culturalization.

\section{Measuring authorial identity}

Pittam et al. (2009) developed the Student Authorship Questionnaire (SAQ) to measure authorial identity among psychology students as a precursor to assessing plagiarism. Since then, the questionnaire has been applied to a number of academic disciplines, namely psychology (Elander et al. 2010; Kinder and Elander 2012), accounting (Ballantine and McCourt Larres 2012; Ballantine, Guo, and Larres 2015) and health (Maguire, Reynolds, and Delahunt 2013). Ballantine, Guo, and Larres (2015) addressed the issue of discipline specificity with respect to authorial identity by drawing on Biglan's (1973a, 1973b) typology which classifies academic disciplines into three dimensions: hard/soft, concerned with the extent to which a paradigm is present; pure/applied, relating to the application of disciplinary knowledge; and life/non-life systems, categorizing disciplines as life or non-life systems. 
Comparing their model with that produced by Pittam et al. (2009), Ballantine, Guo, and Larres (2015) attributed similarities in the factor structure of authorial identity between psychology students (Pittam et al. 2009) and accounting students (Ballantine, Guo, and Larres 2015) to both disciplines sharing a 'soft' identity. Differences in the respective models were explained by reference to the two remaining dimensions of Biglan's (1973a, 1973b) topology, namely the applied/non-life nature of accounting and the pure/life nature of psychology. However, inadequate psychometric testing of Pittam et al.'s (2009) six-factor, 18-item SAQ model resulted in Ballantine, Guo, and Larres (2015) rejecting it in favour of a more psychometrically robust three-factor model which loaded 12 of the 18 original items.

In another recent study, Cheung, Stupple, and Elander (2017) also psychometrically tested the SAQ and, in particular, criticised its content validity. They addressed the issue by applying Lawshe's (1975) content validity ratio to the ratings of 15 Subject Matter Experts with regard to 106 revised authorial identity items. Accordingly, 47 items emerged as content valid. Exploratory factor analysis (EFA) identified a 17-item three-factor model labelled Students' Attitudes and Beliefs about Authorship Scale (SABAS). Confirmatory factor analysis (CFA) reported the SABAS model an adequate fit. After considering multiple reliability coefficients, Cheung, Stupple, and Elander (2017) concluded that their psychometric testing showed SABAS to be a more robust model of authorial identity than either the Pittam et al.'s (2009) six-factor model or Ballantine, Guo, and Larres' (2015) threefactor model.

Cheung, Stupple, and Elander's (2017) major criticism of the SAQ was the questionable content validity. However, notwithstanding the acceptance within psychology that content validity contributes to the validation of an assessment instrument by demonstrating that its 
elements represent the targeted construct for a specific assessment purpose (Haynes, Richard, and Kubany 1995), it should be pointed out that authors in other disciplines have recommended caution in interpretation. For example, research in the health sector suggests that 'where it is necessary to seek expert opinion on item relevance as part of instrument development, then large samples of experts should be employed...and the results should not be interpreted as addressing validity but the acceptability of an operational definition' (Beckstead 2009, 1282).

The current study adopts the original Student Authorship Questionnaire (SAQ) rather than the instrument promoted by Cheung Stupple, and Elander (2017), namely the Students' Attitudes and Beliefs about Authorship Scale (SABAS), to facilitate a meaningful comparison with the findings reported by Ballantine, Guo, and Larres' (2015) who also employed the SAQ. Accordingly, since the students in the Ballantine, Guo, and Larres' (2015) study and those in the current study are both from the same disciplinary background, the issue of culture can be more readily isolated and its impact on authorship and plagiarism more meaningfully determined. The current study acknowledges shortcomings in earlier research into student authorship identified by Cheung, Stupple, and Elander (2017) by applying rigorous statistical testing to assess the psychometric properties of the SAQ in the context of Chinese students.

\section{Method}

\section{Research instrument}

The questionnaire used in the current study consisted of two sections. The first section captured demographic data including gender, age and year of study. The second section included the original 18 SAQ items developed by Pittam et al. (2009) to measure authorial 
identity and was scored by asking respondents to indicate their agreement using a five-point Likert scale, ranging from $1=$ strongly disagree to $5=$ strongly agree.

Both sections of the questionnaire were translated into Chinese using the back-translation method (Brislin 1970). This method required the questionnaire to be translated into Chinese by language experts not involved in its design. The Chinese version was then translated back into English by another language specialist. This process facilitated a comparison between the original and back-translated versions. No discrepancies between the original and the back-translated English version of the questionnaire were identified, indicating that the Chinese version ${ }^{1}$ was an appropriate translation of the original. Ethical approval for the study was obtained prior to distribution of the questionnaire.

\section{Data Collection}

The questionnaire was distributed to accounting and business students at three universities in Beijing during scheduled lectures. Participation in the study was voluntary and students were given approximately 25 minutes to complete the questionnaire. The objective of the study was indicated on the front cover and reiterated by the distributor prior to distribution. A guarantee of confidentiality and anonymity was also provided.

\section{Participants}

A total of 536 responses were obtained from the data collection process. Data collected were screened and cases with missing items removed, leaving 523 complete responses. The dataset comprised $43.6 \%$ male and $56.4 \%$ female students across four years of undergraduate study at three Beijing universities (224 students from University One, 120 students from University Two and 179 students from University Three). Respondents ranged in age from 
17 to 27 , with an average of 20.25 years. All students surveyed were studying accounting and business.

\section{Data analysis strategy}

A two-stage data analysis strategy consisting of exploratory and confirmatory factor analyses was employed. Consistent with prior studies (Cheung, Stupple, and Elander 2017), the data $(\mathrm{N}=523)$ were randomly split into sample 1 (269 cases) and sample 2 (254 cases) to perform independent exploratory and confirmatory factor analyses respectively. Stage one involved conducting an exploratory factor analysis (EFA) to identify the underlying factorial structure of the SAQ. Four issues were considered: the suitability of conducting EFA; the extraction method; the number of factors extracted; and the rotation method. The suitability of conducting EFA was tested using the Kaiser-Meyer-Olkin (KMO) measure of sampling adequacy and Bartlett's test of sphericity (Field 2013). Principal axis factoring (PAF) was selected as the extraction method best suited to dealing with non-normally distributed data (Cheung, Stupple, and Elander 2017). The number of factors to be extracted was determined using three methods (Thompson and Daniel 1996): the eigenvalues-greater-than-one rule (Kaiser 1960); scree plot (Cattell 1966); and parallel analysis (PA) (Horn 1965). PA was performed using polychoric correlation matrices generated by Monte Carlo simulation, thereby producing unbiased estimates of the relationships among variables with ordinal data (Cho, Li, and Bandalos 2009). Glorfeld's (1995) 95th percentile criterion was used across 100 iterations. Factors were extracted when the eigenvalues computed from the real data exceeded those computed from the randomly generated data. Finally, rotation of the extracted factor matrix was addressed to maximise the loading of each variable on one of the extracted factors whilst minimising the loading on all other factors. Direct oblimin was chosen as the rotation method given that the underlying factors were expected to be 
correlated (Field 2013). Factor loadings greater than or equal to 0.50 were selected. While other studies in this area (Pittam et al. 2009; Cheung, Stupple, and Elander 2017) have reported factor loadings below 0.50 , the cut-off applied in the current study is 'considered practically significant' (Hair et al. 2010, 117). Finally, the multicollinearity of the items derived from the EFA was assessed using variance inflation factors (VIF) (Hair et al. 2010).

Stage two involved subjecting the items derived from the EFA to a confirmatory factor analysis (CFA). Modification indices were examined to determine model re-specifications (Hooper, Coughlan, and Mullen, 2008). To assess model fit, a number of statistics were reported: chi-square to degrees of freedom ratio $\left(\chi^{2} / \mathrm{df}\right)$; goodness of fit index (GFI); normed fit index (NFI); comparative fit index (CFI); the root mean square error of approximation (RMSEA); and the standardized root mean square residual (SRMR). The following cut-off values were applied: $<=3$ for $\chi^{2} / \mathrm{df}$ (Kline 2005); $>0.90$ for GFI (Jöreskog and Sörbom 1996); >0.90 for NFI (Hu and Bentler 1999); >0.90 for CFI (Hair et al. 2010). In addition, the combinational rule of RMSEA $<0.06$ and $\mathrm{SRMR}<0.08$ (Hooper, Coughlan, and Mullen, 2008) was utilised. The combinational rule, based on a two-index presentation strategy, is superior to evaluating RMSEA and SRMR separately as it results in 'less sums of Type I and Type II error rates than the single-index presentation strategy' (Hu and Bentler 1999, 23) and is 'extremely sensitive in detecting models with misspecified factor covariance(s)' (26).

To evaluate data fit, three models were tested. Model I is the original 18 item, six-factor SAQ model identified by Pittam et al. (2009). Model II is the three-factor model reported by Ballantine, Guo, and Larres (2015) which developed the work of Pittam et al. (2009) and reported 'substantially better psychometrics' than Model I (Cheung, Stupple, and Elander, 2017, 98). Model III, derived from the results of the EFA in the current study, is a three- 
factor model. Further analysis of the data was undertaken to assess internal consistency reliability. Cronbach's (1951) alpha ( $\alpha$ ) coefficients were calculated to estimate the degree of internal consistency reliability of scores yielded by the research instrument. An acceptance threshold of 0.60 for alpha values is recommended (Bagozzi and Yi 1988). Drawing on the approach adopted by Cheung, Stupple, and Elander (2017), alternative reliability estimates, namely Guttman's (1945) $\lambda_{4}$, McDonald's (1978) $\omega_{\mathrm{h}}$ and $\omega_{\mathrm{t}}$, Revelle's (1979) $\beta$ and Bentler and Woodward's (1980) glb, were calculated for all factors using R software. Revelle (1979) argues that if $\beta$ is less than 0.50 , sub-scales may be present. Finally, internal construct validity, comprising convergent and discriminant validity, was assessed using the average variance extracted (AVE) and by comparing the square roots of AVEs to the correlations between constructs (Hair et al. 2010).

\section{Results}

\section{A Comparison of UK and Chinese students' attitudes to authorial identity and plagiarism}

To facilitate a comparison of UK and Chinese accounting and business students' attitudes to authorial identity and plagiarism, Table 1 presents means and standard deviations using the scoring method identified by Ballantine, Guo, and Larres (2015) ${ }^{2}$. By comparing two datasets which report on students from the same disciplinary background (Biglan's 1973a, 1973b), culture can be isolated more effectively and its impact on authorship and plagiarism more meaningfully determined (Ballantine, Guo, and Larres 2015). Table 1 indicates that mean scores for the three factors for both cohorts are in excess of the median point of the Likert scale (i.e. 3). Further, a comparison of mean scores between the two cohorts suggests that UK and Chinese students report comparable levels of scoring, indicating broadly similar views with respect to all three factors: namely understanding authorship and plagiarism, lack 
of confidence in writing and authorial approach to writing. There is also little volatility in the scores for the three factors, as measured by standard deviations, for both cohorts, providing further evidence of convergence between UK and Chinese accounting and business students' attitudes on authorship and awareness of plagiarism.

Insert Table 1 here

Table 2 reports demographics for the EFA and CFA groups. A t-test indicated no difference between the EFA and CFA groups with regards to age $(\mathrm{t}=0.64, \mathrm{df}=521, \mathrm{p}=0.52)$ while chisquare tests indicated no significant difference in gender $\left(\chi^{2}=1.41, \mathrm{df}=1, \mathrm{p}=0.24\right)$, year of study $\left(\chi^{2}=2.57, \mathrm{df}=3, \mathrm{p}=0.46\right)$ and university $\left(\chi^{2}=0.81, \mathrm{df}=2, \mathrm{p}=0.67\right)$. A t-test, conducted to ascertain whether there was a difference in mean scores for all SAQ items between EFA (Mean=62.60, $\mathrm{SD}=9.91$ ) and CFA samples (Mean=63.65, $\mathrm{SD}=9.17$ ), also indicated no significant difference $(\mathrm{t}=-1.25, \mathrm{df}=521, \mathrm{p}=0.21)$. These findings suggest that the two independent samples are suitable for subsequent factor analyses.

Insert Table 2 here

\section{Exploratory factor analysis (EFA)}

EFA was conducted to explore the factorial structure of the research instrument. The KMO value and Bartlett's test of sphericity provided assurance that the data were suitable for EFA: the KMO value (0.82) exceeded the conventional cut-off value of 0.5 (Kaiser 1974) and Bartlett's test of sphericity $\left(\chi^{2}=2082.34, \mathrm{df}=153, \mathrm{p}=0.001\right)$ was statistically significant, indicating the correlations between variables were significantly different from zero. Given that an examination of skewness and kurtosis for the SAQ items indicated non-normally 
distributed data, principal axis factoring (PAF) was adopted as the extraction method. The eigenvalues-greater-than-one rule identified four factors while both the scree plot test and PA procedure with polychoric correlations identified three factors. Given that both the scree plot test and PA have been reported as providing more accurate results than the eigenvaluesgreater-than-one rule (Fabrigar et al. 1999), three factors were extracted. Finally, direct oblimin rotation was conducted to improve interpretation of the EFA results.

Table 3 presents the results of the EFA. The pattern matrix of rotated factor loadings indicates a total of 12 items with factors loadings greater than or equal to 0.50 (items $5,7,12$, 15, 16, and 18 were discarded). Consistent with Cheung, Stupple, and Elander (2017), the pattern matrix indicated no cross-loadings, reflecting a stable structure in the model. VIF values ranging from 1.30 to 3.20 were calculated. Given that a VIF value of 10 or more is used to indicate high multicollinearity (Hair et al. 2010), these results indicate no threat of multicollinearity. PA using polychoric correlations was conducted to test the validity of the three-factor model for the 12 items. The results confirmed that the three factors extracted from the real data had greater eigenvalues than the 95th percentile of those extracted from the simulated data (Glorfeld 1995).

Insert Table 3 here

The EFA results identified three factors accounting for $30.24 \%, 15.79 \%$ and $8.68 \%$ of the total variance respectively. The first factor, comprising five items (1, 2, 3, 4, and 8), replicated factor one, understanding authorship and plagiarism, reported by Ballantine, Guo, and Larres (2015). The second factor included four items $(6,9,10$, and 11), three of which are consistent with factor two reported by Ballantine, Guo, and Larres (2015). This factor has 
been re-labelled incorporating others' writing to reflect the fact that, rather than indicating an overall lack of confidence in writing, as indicated in Ballantine, Guo, and Larres (2015), this latent variable now reflects a greater emphasis on intertextuality. The third factor comprised three items $(13,14$, and 17), two of which are consistent with factor 3 identified in the Ballantine, Guo, and Larres model. Given that this latent variable measures the same aspect of authorial identity as Ballantine, Guo, and Larres' (2015) factor three, the label authorial approach to writing has been retained.

\section{Confirmatory factor analysis (CFA)}

CFA model fit statistics are reported in Table 4. For comparison purposes CFA was conducted on three models. Model I, the original SAQ model (Pittam et al. 2009) did not provide an acceptable fit to the data $\left(\chi^{2} / \mathrm{df}=3.20, \mathrm{GFI}=0.87, \mathrm{NFI}=0.80, \mathrm{CFI}=0.85\right.$, RMSEA=0.093, SRMR=0.096). Model II (Ballantine, Guo, and Larres 2015) provided an acceptable fit to the data $\left(\chi^{2} / \mathrm{df}=2.09, \mathrm{GFI}=0.94, \mathrm{NFI}=0.90, \mathrm{CFI}=0.95\right)$ with one exception, namely the RMSEA element of the combinational rule failed to meet the criterion established by Hooper, Coughlan, and Mullen (2008) (RMSEA=0.066, SRMR=0.056). Model III provided a better fit $\left(\chi^{2} / \mathrm{df}=1.62, \mathrm{GFI}=0.95, \mathrm{NFI}=0.92, \quad \mathrm{CFI}=0.97, \quad \mathrm{RMSEA}=0.050\right.$, $\mathrm{SRMR}=0.053$ ) than Model II in that, as well as exceeding all cut-off values, it satisfied the combinational rule. Additionally, given that Mardia's coefficient for multivariate kurtosis was 34.05 (critical ratio=14.80), indicating multivariate non-normality, bootstrapping (Bollen and Stine 1993) was adopted for Model III using 2,000 samples (Cheung, Stupple, and Elander 2017). Bootstrapped standardized regression coefficients were identical to those of Model III, up to three decimal places, indicating no threat of non-normality. The CFA results confirm that Model III (see Figure 1) provides the best fit to the Chinese data and is, therefore, the preferred model. 
Insert Table 4 here

Insert Figure 1 here

\section{Internal consistency reliability}

Cronbach's alpha $(\alpha)$ coefficients, reported in Table 5, Panel A, were acceptable (Bagozzi and Yi 1988) for each of the three factors making up Model III: understanding authorship and plagiarism $(\alpha=0.81)$; incorporating others' writing $(\alpha=0.79)$; authorial approach to writing $(\alpha=0.66)$; and the overall 12 items $(\alpha=0.79)$. Panel A also reports the means and standard deviations for the three factors making up Model III to facilitate meaningful 'comparisons ... with future studies in alternative disciplines and settings' (Ballantine, Guo and Larres 2015, 604). Additional reliability coefficients are reported in Table 5, Panel B. Consistent with Cheung, Stupple, and Elander (2017), the coefficients ( $\beta, \omega_{\mathrm{h}}, \omega_{\mathrm{t}}, \mathrm{glb}$, and $\left.\lambda_{4}\right)$ provide evidence that the internal consistency of Model III and the individual factors were good.

Insert Table 5 here

\section{Construct Validity of Measurement Model}

The internal construct validity of Model III was examined in terms of convergent validity and discriminant validity (Table 6). The results showed that AVE values of the three factors (0.513, 0.545, and 0.538) exceeded the conventional threshold of 0.50 (Hair et al. 2010), providing evidence of good convergent validity within the model. Discriminant validity is present if the square root of AVE is greater than the correlation between constructs in that 'a latent construct could explain more of the variance in its item measures that it shares with 
another construct' (Hair et al. 2010, 710). The results show that the square roots of AVEs were all greater than their respective correlations, providing evidence of good discriminant validity. Taken together these findings indicate that Model III possesses good internal construct validity.

\author{
Insert Table 6 here
}

\title{
Discussion
}

The current study draws on Pittam et al.'s (2009) Student Authorship Questionnaire (SAQ) to explore authorial identity among Chinese students studying accounting and business in China. It compares Chinese students' attitudes to authorship and plagiarism with those of UK accounting students reported by Ballantine, Guo, and Larres (2015) and provides interesting insights into the relative sense Chinese students have of themselves as authors. The study also investigates the psychometric properties of the SAQ in the context of Chinese students and offers a distinct model for scoring the instrument which is subtly different to that reported by Ballantine, Guo, and Larres (2015). The resulting Chinese model reflects the paradox of the Chinese learner. Overall, the study presents findings which inform cross-cultural awareness of authorial identity and plagiarism.

A contemporary perspective of Chinese business and accounting students' attitudes to their authorial identity and plagiarism is presented. A comparison of mean scores and standard deviations derived from the SAQ provides evidence that Chinese students do not exhibit greater authorial naivety than their UK counterparts. Rather, the two cohorts appear to share an understanding of authorship and an appreciation of the seriousness of plagiarism despite 
experiencing education in different cultural contexts. Accordingly, it would appear that the traditional view of Chinese students not taking ownership of their writing and being unaware of plagiarism as an academic transgression is unwarranted. This apparent cultural shift in attitudes to authorship and plagiarism may well reflect recent efforts to internationalise higher education in China at university and national level. The imposition of strict anti-plagiarism measures by Chinese universities is likely to have impacted on students and exerted a proximate influence on their perception of plagiarism as an unacceptable practice. Further, recent government-funded initiatives aimed at developing research of international standing in China are likely to be improving awareness within the academic community of how to provide appropriate references for citations and quotations. Accordingly, these developments, aimed at the academic community may, in turn, be having a trickle-down effect on attitudes to authorship and cognizance of plagiarism among Chinese students.

The study also undertook rigorous statistical testing to assess the psychometric properties of the SAQ in the context of Chinese students. The results of a two-stage factor analysis produced a three-factor model which possessed substantially better psychometric properties than Pittam et al.'s (2009) original six-factor SAQ model. Furthermore, the resulting Chinese three-factor model displayed interesting factorial similarities with the UK model reported by Ballantine, Guo, and Larres (2015). Factor one of the Chinese model replicated Ballantine, Guo, and Larres' (2015) factor one, understanding authorship and plagiarism. Identical observed variables reflecting a strong sense of authorial identity were loaded into the same latent variable in both studies. In addition, factors two and three of the Chinese model corresponded closely to factors two and three of the model reported by Ballantine, Guo, and Larres (2015). In both studies these sub-scales contained items representing a pragmatic approach to writing (associated with a strategic approach to learning (Pittam et al. 2009)) and 
a top-down approach to writing, (associated with a deep approach to learning (Pittam et al. 2009)). However, two items representing confidence in writing in the UK model (one in factor two and one in factor three) failed to load onto the Chinese model and were replaced by items reflecting a bottom-up approach to writing, not present in the UK model. These bottom-up items (associated with surface learning (Pittam et al. 2009)) reflect the way in which Chinese learners traditionally acquire knowledge through rote learning (Biggs 1994). When these bottom-up items are combined with the pragmatic and top-down items, the Chinese model appears to represent the complex nature of the Chinese learner wherein deeper knowledge is acquired by adopting surface learning techniques. This key finding distinguishes the Chinese model from the UK model. Moreover, the presence of Pittam et al.'s (2009) approaches to writing sub-scales (i.e. bottom-up, pragmatic and top-down) in the Chinese model provides evidence that approaches to writing constitute a key aspect of the authorial identity construct of Chinese students. This finding contrasts with that of Cheung Stupple, and Elander (2017) who concluded that 'although approaches to writing are an important consideration for writing instructors ... they are not a key attribute of authority identity' (109).

The study is particularly timely and relevant given the significant number of Chinese students enrolling in UK higher education. The findings inform academics that attitudes to authorial identity and plagiarism among Chinese business and accounting students appear to correspond more closely to those of their UK counterparts than has hitherto been suggested in the literature or reported in the popular press. In so doing, the study highlights the importance of not 'assuming deficiencies in moral frames of reference' (Hu and Lei 2015, 233). In addition, the Chinese model makes an important contribution to the student authorial identity literature on two levels. First, it contests the proposition put forward by Cheung, 
Stupple, and Elander (2017) that 'approaches to writing scales are not part of the core authorial identity construct' (97) and secondly, it offers a distinct and subtly different method for scoring the SAQ which takes account of the paradox of the Chinese learner and successfully captures Chinese students' authorial identity and cognizance of plagiarism. 


\section{References}

Abasi, A. R., N. Akbari, and B. Graves. 2006. "Discourse Appropriation, Construction of Identities, and the Complex Issue of Plagiarism: ESL Students Writing in Graduate School.” Journal of Second Language Writing 15 (2): 102-117.

Aftab, A. 2016. 'UK universities in 'plagiarism epidemic' as almost 50,000 students caught cheating over last 3 years". Independent. 4 January. Accessed 15 July 2016. http://www.independent.co.uk/student/news/uk-universities-in-plagiarism-epidemic-asalmost-50000-students-caught-cheating-over-last-3-years-a6796021.html

Bagozzi, R. P., and Y. Yi. 1988. "On the Evaluation of Structural Equation Models.” Journal of the Academy of Marketing Science 16 (2): 74-94.

Ballantine, J., X. Guo, and P. Larres. 2015. "Psychometric Evaluation of the Student Authorship Questionnaire: A Confirmatory Factor Analysis Approach.” Studies in Higher Education 40 (4): 596-609.

Ballantine, J., and P. McCourt Larres. 2012. "Perceptions of Authorial Identity in Academic Writing among Undergraduate Accounting Students: Implications for Unintentional Plagiarism." Accounting Education: an international journal 21 (3): 289-306.

Beckstead, J. W. 2009. "Content Validity is Naught." International Journal of Nursing Studies 46 (9): 1274-1282. 
Bentler, P., and J. Woodward. 1980. "Inequalities among Lower Bounds to Reliability: With Applications to Test Construction and Factor Analysis." Psychometrika 45 (2): 249-267.

Biggs, J. 1994. “Asian Learners through Western Eyes: An Astigmatic Paradox.” Australian and New Zealand Journal of Vocational Education Research 2 (2): 40-63.

Biglan, A. 1973a. "The Characteristics of Subject Matter in Different Academic Areas." Journal of Applied Psychology 57 (3): 195-203.

Biglan, A. 1973b. "Relationships between Subject Matter Characteristics and the Structure and Output of University Departments.” Journal of Applied Psychology 57 (3): 204-213.

Bollen, K. A., and R. A. Stine. 1993. "Bootstrapping Goodness-of-Fit Measures in Structural Equation Modeling.” In Testing Structural Equation Models, edited by K. A. Bollen and J. S. Long, 111-135. Newbury Park: Sage.

Brislin, R. W. 1970. "Back-translation for Cross-Cultural Research.” Journal of CrossCultural Psychology 1 (3): 185-216.

Cattell, R. B. 1966. "The Scree Test for the Number of Factors." Multivariate Behavioural Research 1 (2): 245-276.

Chan, S. 1999. "The Chinese Learner - A Question of Style." Education + Training 41 (6/7): 294-304. 
Cheung, K. Y. F., E. J. N. Stupple, and J. Elander. 2017. "Development and Validation of the Student Attitudes and Beliefs about Authorship Scale: A Psychometrically Robust Measure of Authorial Identity." Studies in Higher Education. 42 (1): 97-114.

Cho, S., F. Li, and D. Bandalos. 2009. “Accuracy of the Parallel Analysis Procedure with Polychoric Correlations." Educational and Psychological Measurement 69 (5): 748-759.

Cooper, B. J. 2004. "The Enigma of the Chinese Learner." Accounting Education: an international journal 13 (3): 289-310.

Cronbach, L. J. 1951. "Coefficient Alpha and the Internal Structure of Tests.” Psychometrika 16 (3): $297-334$.

Duff, P. A. 2010. "Language Socialization into Academic Discourse Communities." Annual Review of Applied Linguistics 30: 169-192.

The Economist. 2013. "Campus Collaboration." 5 January. Accessed 15 July 2016. http://www.economist.com/news/china/21569070-foreign-universities-find-working-chinaharder-they-expected-campus-collaboration

Ehrich, J., S. J. Howard, C. Mu, and S. Bokosmaty. 2016. "A Comparison of Chinese and Australian University Students Attitudes towards Plagiarism.” Studies in Higher Education $41(2): 231-246$. 
Elander, J., G. Pittam, J. Lusher, P. Fox, and N. Payne. 2010. "Evaluation of an Intervention to Help Students Avoid Unintentional Plagiarism by Improving their Authorial Identity." Assessment and Evaluation in Higher Education 34 (1): 1-15.

Fabrigar, L. R., D. T. Wegener, R. C. MacCallum, and E. J. Strahan. 1999. "Evaluating the Use of Exploratory Factor Analysis in Psychological Research.” Psychological Methods 4 (3): 272-299.

Field, A. 2013. Discovering Statistics Using IBM SPSS Statistics. London: Sage.

Glorfeld, L. W. 1995. “An Improvement on Horn's Parallel Analysis Methodology for Selecting the Correct Number of Factors to Retain." Educational and Psychological Measurement 55 (3), 377-393.

Guo, C., Y. Man, and P. Hao. 2013. "Management and effect on plagiarism of undergraduates' graduation thesis." Experimental Technology and Management 30 (3): 130134.

Guttman, L. 1945. “A Basis for Analyzing Test-Retest Reliability.” Psychometrika 10 (4): 255-282.

Hair, J. F., W. C. Black, B. J. Babin, and R. E. Anderson. 2010. Multivariate Data Analysis: A Global Perspective. Upper Saddle River, New Jersey: Pearson Education. 
Haynes, S. N., D. R. Richard, and E. S. Kubany. 1995. "Content Validity in Psychological Assessment: A Functional Approach to Concepts and Methods." Psychological Assessment 7 (3): $238-247$.

HESA (Higher Education Statistics Agency). 2016. "Press Office: Headline Statistics." Accessed 15 July 2016. https://www.hesa.ac.uk/press

Hooper, D., J. Coughlan, and M. Mullen. 2008. "Structural Equation Modelling: Guidelines for Determining Model Fit." Electronic Journal of Business Research Methods: 6 (1): 53-60.

Horn, J. L. 1965. "A Rationale and Test for the Number of Factors in Factor Analysis." Psychometrika 30 (2): 179-185.

Hu, L., and P. M. Bentler. 1999. "Cut-off Criteria for Fit Indices in Covariance Structure Analysis: Conventional Versus New Alternatives." Structural Equation Modelling 6 (1): 1-55.

Hu, G., and J. Lei. 2012. "Investigating Chinese University Students' Knowledge of and Attitudes toward Plagiarism from an Integrated Perspective." Language Learning: a journal of research in language studies 62 (3): 813-850.

Hu, G., and J. Lei. 2015. “Chinese University Students' Perceptions of Plagiarism.” Ethics \& Behavior 25 (3): 233-255.

Jöreskog, K. G. and D. Sörbom. 1996. LISREL 8 User's Reference Guide. Uppsala, Sweden: Scientific Software International. 
Kaiser, H. F. 1960. "The Application of Electronic Computers to Factor Analysis." Educational and Psychological Measurement 20 (1): 141-151.

Kaiser, H. F. 1974. “An Index of Factorial Simplicity.” Psychometrika 39 (1): 31-36.

Kinder, J., and J. Elander. 2012. "Dyslexia, Authorial Identity, and Approaches to Learning and Writing: A Mixed Methods Study." British Journal of Educational Psychology 82 (2): 289-307.

Kline, R. B. 2005. Principles and Practice of Structural Equation Modeling. New York: Guildford Press.

Lawshe, C. H. 1975. “A Quantitative Approach to Content Validity.” Personnel Psychology 28 (4): $563-75$.

Lei, J., and G. Hu. 2015. "Chinese University EFL Teachers' Perceptions of Plagiarism." Higher Education 70 (3): 551-565.

Ma, Y., D. L. McCabe, and R. Liu. 2013. "Students' Academic Cheating in Chinese Universities: Prevalence, Influencing Factors, and Proposed Action", Journal of Business Ethics 11 (3): 169-184. 
Maguire, M., A. E. Reynolds, and B. Delahunt. 2013. "Self-efficacy in Academic Reading and Writing, Authorial Identity and Learning Strategies in First-Year Students." All Ireland Journal of Teaching and Learning in Higher Education 5 (1): 1111-1117.

Martin, D. E. 2012. "Culture and Unethical Conduct: Understanding the Impact of Individualism and Collectivism on Actual Plagiarism." Management Learning 43 (3): 261273.

McDonald, R. P. 1978. "Generalizability in Factorable Domains: 'Domain Validity and Generalizability'." Educational and Psychological Measurement 38 (1): 75-79.

The Ministry of Education of the People's Republic of China. 2009. "Regulations on a serious process of academic misconduct", Beijing, China: The Central People's Government of the People's Republic of China.

The Ministry of Education of the People's Republic of China. 2012. "Regulations on Academic dishonesty in dissertations", Beijing, China: The Central People's Government of the People's Republic of China.

Peak, M. 2015. "UK is top host of international students, but for how long?" British Council. 24 February. Accessed 15 July 2016. https://www.britishcouncil.org/voices-magazine/uk-tophost-international-students-how-long

Pecorari, D., and B. Petrić. 2014. "Plagiarism in Second-language Writing." Language Teaching 47 (3): 269-302. 
Peng, K., and R. E. Nesbitt. 1999. "Culture, Dialectics, and Reasoning about Contradiction.” American Psychologist 54 (9): 741-754.

Pittam, G., J. Elander, J. Lusher, P. Fox, and N. Payne. 2009. "Student Beliefs and Attitudes about Authorial Identity in Academic Writing." Studies in Higher Education 34 (2): 153-170.

Revelle, W. 1979. "Hierarchical Clustering and the Internal Structure of Tests.” Multivariate Behavior Research 14 (1): 59-69.

Sharma, Y. 2013. "Regulation on academic fraud hopes to reduce plagiarism", University World News, (253), 6 January. Accessed $15 \quad$ July 2016. http://www.universityworldnews.com/article.php?story=20130104202607303

Shi, L. 2004. "Textual Borrowing in Second-language Writing." Written Communication 21 (2): 171-200.

Snowden, C. 2005. "Plagiarism and the culture of multilingual students in higher education abroad." ELT Journal 59: 226-233.

Thompson, B., and L. G. Daniel. 1996. "Factor Analytic Evidence for the Construct Validity of Scores: A Historical Overview and Some Guidelines." Educational and Psychological Measurement 56(2): 197-208. 
UKCISA (UK Council for International Students Affairs). 2016. "International student statistics: UK higher education." Accessed 15 July 2016. https://www.hesa.ac.uk/index.php?option=com pubs\&Itemid=\&task=show year\&pubId=1\& versionId $=25 \&$ yearId $=325$

Yang, R., and A. Welch. 2012. "A world-class university in China? The case of Tsinghua". Higher Education 63 (5): 645-666. 
Table 1:

A Comparison of Means and Standard Deviations between UK and Chinese Students measured using Ballantine, Guo, and Larres' (2015) Sub-Scales

\begin{tabular}{|l|c|c|c|c|}
\hline & \multicolumn{2}{|c|}{$\begin{array}{c}\text { UK sample } \\
\text { (n=588) }\end{array}$} & \multicolumn{2}{|c|}{$\begin{array}{c}\text { Chinese sample } \\
\text { (n=523) }\end{array}$} \\
\hline Ballantine et al.'s (2015) factors & Mean & $\begin{array}{c}\text { Standard } \\
\text { Deviation }\end{array}$ & Mean & $\begin{array}{l}\text { Standard } \\
\text { Deviation }\end{array}$ \\
\hline $\begin{array}{l}\text { Factor 1: Understanding authorship } \\
\text { and plagiarism }\end{array}$ & 3.92 & 0.61 & 3.76 & 0.76 \\
\hline Factor 2: Lack of confidence in writing & 3.05 & 0.70 & 3.01 & 0.48 \\
\hline $\begin{array}{l}\text { Factor 3: Authorial approach to } \\
\text { writing }\end{array}$ & 3.29 & 0.65 & 3.37 & 0.74 \\
\hline
\end{tabular}


Table 2: Descriptive statistics - Exploratory Factor Analysis (EFA) and Confirmatory Factor Analysis (CFA) Samples

\begin{tabular}{|c|c|c|c|}
\hline & $E F A$ & $C F A$ & $\begin{array}{l}\text { Comparison } \\
\text { (t/chi-square statistic, } d f, p)\end{array}$ \\
\hline Sample size & $\mathrm{N}=269(51.4 \%)$ & $\mathrm{N}=254(48.6 \%)$ & \\
\hline Age & $\begin{array}{c}\mathrm{Mean}=20.30 \\
\mathrm{SD}=1.62 \\
\mathrm{Min}=17 \\
\mathrm{Max}=27\end{array}$ & $\begin{array}{c}\text { Mean }=20.20 \\
\mathrm{SD}=1.67 \\
\mathrm{Min}=18 \\
\mathrm{Max}=26\end{array}$ & $\mathrm{t}=0.64, \mathrm{df}=521, \mathrm{p}=0.52$ \\
\hline $\begin{array}{l}\text { Gender } \\
\text { Male } \\
\text { Female }\end{array}$ & $\begin{array}{l}124(46.1 \%) \\
145(53.9 \%)\end{array}$ & $\begin{array}{l}104(40.9 \%) \\
150(59.1 \%)\end{array}$ & Chi-square $=1.41, \mathrm{df}=1, \mathrm{p}=0.24$ \\
\hline $\begin{array}{l}\text { Year of study } \\
\text { Year one } \\
\text { Year two } \\
\text { Year three } \\
\text { Year four }\end{array}$ & $\begin{array}{c}54(20.1 \%) \\
128(47.6 \%) \\
56(20.8 \%) \\
31(11.5 \%)\end{array}$ & $\begin{array}{c}64(25.2 \%) \\
106(41.7 \%) \\
53(20.9 \%) \\
31(12.2 \%)\end{array}$ & Chi-square $=2.57, \mathrm{df}=3, \mathrm{p}=0.46$ \\
\hline $\begin{array}{l}\text { University } \\
\text { One } \\
\text { Two } \\
\text { Three }\end{array}$ & $\begin{array}{c}115(42.8 \%) \\
58(21.6 \%) \\
96(35.7 \%)\end{array}$ & $\begin{array}{c}109(42.9 \%) \\
62(24.4 \%) \\
83(32.7 \%)\end{array}$ & Chi-square $=0.81, \mathrm{df}=2, \mathrm{p}=0.67$ \\
\hline
\end{tabular}


Table 3: Pattern Matrix of Rotated Factor Loadings

\begin{tabular}{|c|c|c|c|c|}
\hline & Item & $\begin{array}{c}\text { Factor } \\
1\end{array}$ & $\begin{array}{c}\text { Factor } \\
2\end{array}$ & $\begin{array}{c}\text { Factor } \\
3\end{array}$ \\
\hline Item 1 & $\begin{array}{l}\text { I know what it means to be the author of a piece of written } \\
\text { work }\end{array}$ & 0.64 & & \\
\hline Item 2 & I know what the responsibilities of an author are & 0.83 & & \\
\hline Item 3 & I would never be accused of plagiarism & 0.50 & & \\
\hline Item 4 & $\begin{array}{l}\text { I know how to provide references for citations and quotations } \\
\text { in my written work }\end{array}$ & 0.80 & & \\
\hline Item 8 & $\begin{array}{l}\text { I know how to show which parts of my assignments were not } \\
\text { written by me }\end{array}$ & 0.56 & & \\
\hline Item 6 & I find it difficult to express my subject in my own words & & 0.63 & \\
\hline Item 9 & $\begin{array}{l}\text { Writing an assignment is all about finding material in books, } \\
\text { journals and the Internet and arranging it in the form of an } \\
\text { essay }\end{array}$ & & 0.80 & \\
\hline Item 10 & $\begin{array}{l}\text { I just don't have time to put everything in my own words } \\
\text { when writing an assignment }\end{array}$ & & 0.57 & \\
\hline Item 11 & $\begin{array}{l}\text { I get better marks when I use more material taken directly } \\
\text { from books, journals or the internet in my assignments }\end{array}$ & & 0.75 & \\
\hline Item 13 & $\begin{array}{l}\text { When writing an assignment I begin by looking for material I } \\
\text { can include and then think about how I can put it together }\end{array}$ & & & 0.77 \\
\hline Item 14 & $\begin{array}{l}\text { Writing an assignment is all about making an argument based } \\
\text { on my own thoughts about the subject }\end{array}$ & & & 0.62 \\
\hline Item 17 & $\begin{array}{l}\text { I get higher marks by writing more of my assignments in my } \\
\text { own words }\end{array}$ & & & 0.54 \\
\hline
\end{tabular}

Note: Items with a factor loading lower than 0.5 have been removed. 
Table 4: Confirmatory Factor Analysis Model Fit Statistics

\begin{tabular}{lllllllll}
\hline \multicolumn{1}{c}{ Model } & $\chi^{2}$ & $\boldsymbol{d f}$ & $\chi^{2} / \boldsymbol{d f}$ & $\boldsymbol{G F I}$ & $\boldsymbol{N F I}$ & $\boldsymbol{C F I}$ & $\boldsymbol{R M S E A}$ & SRMR \\
\hline \hline $\begin{array}{l}\text { Model I } \\
\text { (Pittam et al. 2009) }\end{array}$ & 358.85 & 112 & 3.20 & 0.87 & 0.80 & 0.85 & 0.093 & 0.096 \\
$\begin{array}{l}\text { Model II } \\
\text { (Ballantine, Guo, } \\
\text { and Larres 2015) }\end{array}$ & 89.87 & 43 & 2.09 & 0.94 & 0.90 & 0.95 & 0.066 & 0.056 \\
Model III & & & & & & & & \\
\hline
\end{tabular}


Table 5: Internal consistency reliability (Model III)

Panel A: Cronbach's Alpha Coefficients, Means and Standard Deviations

\begin{tabular}{llccccc}
\hline & & $\begin{array}{c}\text { Cronbach's } \\
\text { Alpha(a) }\end{array}$ & $\begin{array}{c}\text { Number } \\
\text { of Items }\end{array}$ & Items & Mean & $\begin{array}{c}\text { Standard } \\
\text { deviation }\end{array}$ \\
\hline \hline Factor 1 & $\begin{array}{l}\text { Understanding } \\
\text { authorship and } \\
\text { plagiarism }\end{array}$ & 0.81 & 5 & $1,2,3,4,8$ & 3.76 & 0.76 \\
Factor 2 & $\begin{array}{l}\text { Incorporating } \\
\text { others' writing } \\
\text { Fuctor 3 }\end{array}$ & 0.79 & 4 & $6,9,10,11$ & 2.86 & 0.87 \\
$\begin{array}{l}\text { Authorial approach } \\
\text { to writing }\end{array}$ & 0.66 & 3 & $13,14,17$ & 3.60 & 0.75 \\
$\begin{array}{l}\text { Overall } \\
\text { reliability }\end{array}$ & All 12 items & 0.79 & 12 & & & \\
\hline
\end{tabular}

Panel B: Additional Reliability Estimates

\begin{tabular}{lccccc}
\hline & $\begin{array}{c}\text { Revelle's } \\
(1979) \beta\end{array}$ & $\begin{array}{c}\text { McDonald's } \\
(1978) \omega_{h}\end{array}$ & $\begin{array}{c}\text { McDonald's } \\
(1978) \omega_{t}\end{array}$ & $\begin{array}{c}\text { Bentler and } \\
\text { Woodward's (1980) } \\
\text { glb }\end{array}$ & $\begin{array}{c}\text { Guttman's } \\
(1945) \lambda_{4}\end{array}$ \\
\hline \hline Factor 1 & 0.71 & 0.84 & 0.90 & 0.87 & 0.86 \\
Factor 2 & 0.74 & 0.86 & 0.83 & 0.79 & 0.82 \\
Factor 3 & 0.59 & 0.87 & 0.77 & 0.66 & 0.64 \\
Overall & 0.58 & 0.85 & 0.86 & 0.89 & 0.94 \\
reliability & & & & & \\
\hline
\end{tabular}


Table 6: Construct Validity of Measurement Model III

\begin{tabular}{lcccc}
\hline & AVE & $\begin{array}{c}\text { Square root of } \\
\text { AVE }\end{array}$ & \multicolumn{2}{c}{ Correlation } \\
\hline \hline & & & Factor 1 & Factor 2 \\
Factor 1 & 0.513 & 0.716 & & \\
Factor 2 & 0.545 & 0.738 & $0.18^{* *}$ & \\
Factor 3 & 0.538 & 0.733 & $0.44^{* *}$ & $0.28^{* *}$ \\
\hline
\end{tabular}

Notes: AVE (average variance extracted)

** Significant at $p<0.05$ 
Figure 1: Chinese Model for Scoring the SAQ

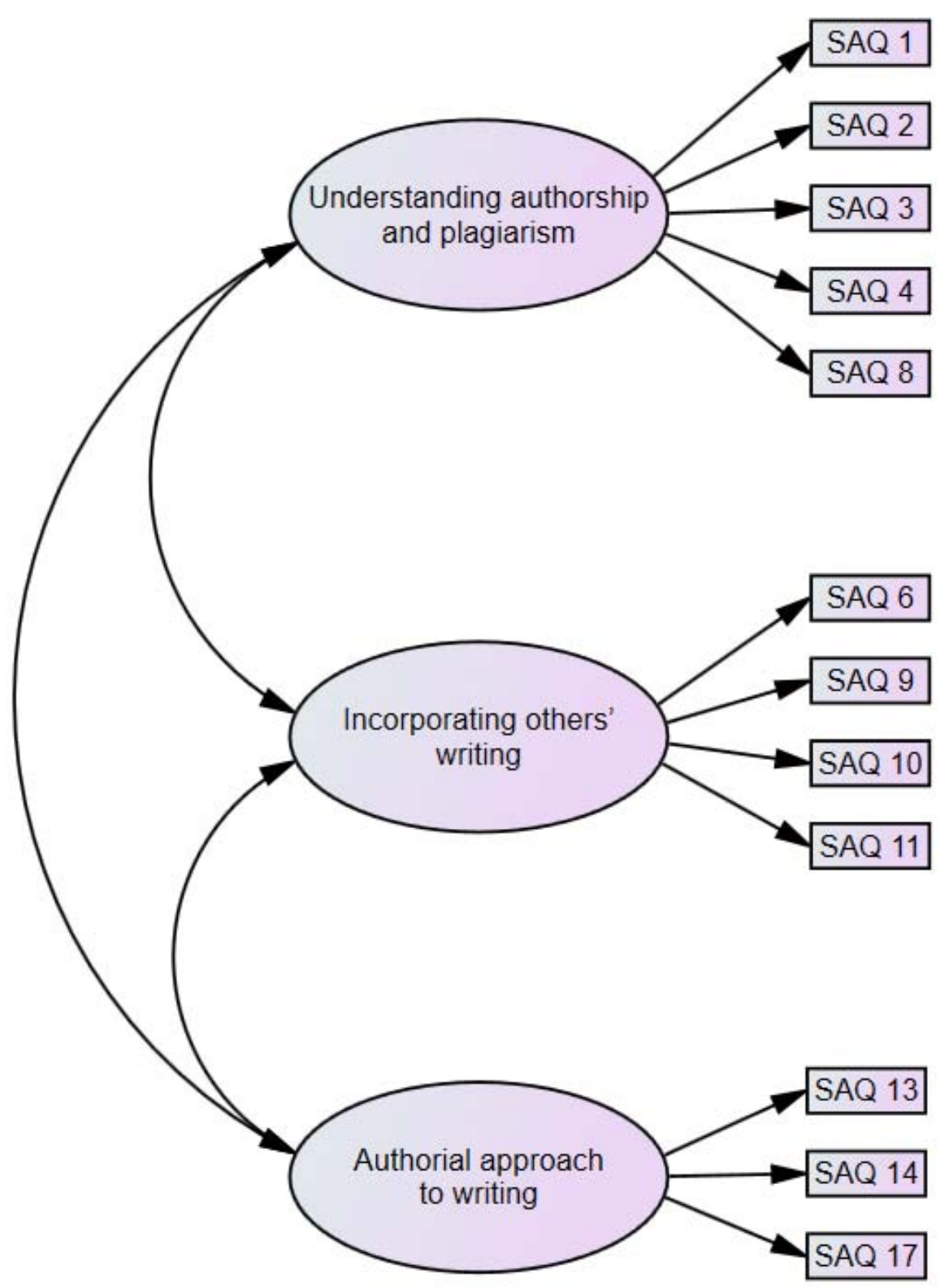

\section{Notes}

1. A copy of the Chinese translation of the SAQ is available from the authors on request.

2. Means and standard deviations of sub-scales for UK students were obtained from Table 3, Panel B, Ballantine, Guo, and Larres (2015). Since Ballantine, Guo, and Larres (2015) only report at sub-scale level, it was not possible to report a comparison of means and standard deviations among individual items in the current study. Furthermore, tests of statistically significant difference could not be undertaken. 